\title{
GMR
}

\section{In vitro expansion and differentiation of rat pancreatic duct-derived stem cells into insulin secreting cells using a dynamic three-dimensional cell culture system}

\author{
X.C. Chen, H. Liu, H. Li, Y. Cheng, L. Yang and Y.F. Liu \\ Department of General Surgery, Organ Transplant Unit, \\ First Affiliated Hospital, China Medical University, Shenyang, \\ Liaoning Province, Shenyang, China \\ Corresponding authors: H. Liu / Y.F. Liu \\ E-mail: liuhaodoctor@hotmail.com / yfliu1952@sina.com \\ Genet. Mol. Res. 15 (2): gmr. 15028808 \\ Received May 16, 2016 \\ Accepted June 3, 2016 \\ Published June 24, 2016 \\ DOI http://dx.doi.org/10.4238/gmr.15028808
}

\begin{abstract}
In this study, a dynamic three-dimensional cell culture technology was used to expand and differentiate rat pancreatic ductderived stem cells (PDSCs) into islet-like cell clusters that can secrete insulin. PDSCs were isolated from rat pancreatic tissues by in situ collagenase digestion and density gradient centrifugation. Using a dynamic three-dimensional culture technique, the cells were expanded and differentiated into functional islet-like cell clusters, which were characterized by morphological and phenotype analyses. After maintaining $1 \times 10^{8}$ isolated rat PDSCs in a dynamic three-dimensional cell culture for 7 days, $1.5 \times 10^{9}$ cells could be harvested. Passaged PDSCs expressed markers of pancreatic endocrine progenitors, including CD29 (86.17\%), CD73 (90.73\%), CD90 (84.13\%), CD105 (78.28\%), and Pdx-1. Following 14 additional days of culture in serumfree medium with nicotinamide, keratinocyte growth factor (KGF), and $\beta$ fibroblast growth factor (FGF), the cells were differentiated into islet-
\end{abstract}


like cell clusters (ICCs). The ICC morphology reflected that of fused cell clusters. During the late stage of differentiation, representative clusters were non-adherent and expressed insulin indicated by dithizone (DTZ)-positive staining. Insulin was detected in the extracellular fluid and cytoplasm of ICCs after 14 days of differentiation. Additionally, insulin levels were significantly higher at this time compared with the levels exhibited by PDSCs before differentiation $(\mathrm{P}<0.01)$. By using a dynamic three-dimensional cell culture system, PDSCs can be expanded in vitro and can differentiate into functional islet-like cell clusters.

Key words: Dynamic three-dimensional culture; Islet $\beta$-cells; Pancreatic duct-derived stem cells

\section{INTRODUCTION}

Islet transplantation is an effective treatment of diabetes, but donor shortage limits its clinical application. Research has increasingly focused on developing new sources of islet cells (Ramiya et al., 2000; Shapiro et al., 2006; Chhabra and Brayman, 2013; Schiesser and Wells 2014). It has been reported that fat cells, bone marrow stem cells, skin cells, and embryonic stem cells can be differentiated into cells that are able to secrete insulin (Bhonde et al., 2014). However, these potential sources are not yet studied to support clinical applications and some studies have raised ethical concerns. Because pancreatic duct-derived stem cells (PDSCs) are also isolated from the pancreas and are of the same embryological origin as islet cells, they may present differentiation advantages over other stem cells. As adult stem cells, PDSCs are easy to manipulate, exhibit high success rates, and show lower tumorigenicity and lower social and ethical barriers. PDSCs are thus considered to present a broader application potential (Bonner-Weir and Weir, 2005).

Using the current cell culture technology, islet-like cells obtained by differentiation of stem cells resemble the islets of Langerhans. However, they cannot be used for clinical cell replacement therapies because they do not function like mature islets. Specific reasons include: 1) The islet-like structures present a low proportion of endocrine cells, and the cells lack interconnections; 2) the stem cell-derived $\beta$ cells lack insulin-secreting particles inside their cytoplasm; 3) the cells do not exhibit an acute insulin secreting response to glucose stimulation; 4) the synthesis and release of insulin by these cells are significantly lower than normal; and 5) the islet-like structures contain a large number of undifferentiated or partially differentiated precursor cells (Minami and Seino 2013). Therefore, current cell culture techniques need further improvement.

One way to improve cell culture for differentiation is by mimicking the microenvironment that surrounds differentiating cells in vitro. Three-dimensional cell culture is a new technology that allows the culture of cells in vitro in three-dimensional scaffolds of different materials (Wang et al., 2006). The cells are able to migrate, grow, and form three-dimensional cell-scaffold complexes. These complexes may fully simulate the in vivo microenvironment. In this study, we isolated duct cells from rat pancreatic tissue. We then employed a dynamic three-dimensional cell culture technology to expand and differentiate these cells into islet-like cell clusters (ICCs) that were able to secrete insulin. 


\section{MATERIAL AND METHODS}

\section{Animals and reagents}

Adult male Wistar rats, weighing 200-300 g each, were provided by the experimental animal center of China Medical University. The experimental protocol was approved by the Animal Care Committee of China Medical University. The dynamic three-dimensional cell culture system (BelloStage-3000, CESCO Bioengineering, Taichung, Taiwan), Collagenase type V, bovine serum albumin (BSA), nicotinamide, Ficoll 400 (Sigma, St Louis, MO, USA), Hank's buffered saline solution (HBSS), Roswell Park Memorial Institute (RPMI) 1640 (Hyclone, South Logan, UT, USA), DTZ, Matrigel (BD Bioscience, Mountain View, CA, USA), $\beta$-FGF (Peprotech, Rocky Hill, NJ, USA), KGF (Roche, Basel, Switzerland), and bicinchoninic acid (BCA) protein assay kit (Pierce, Logan, UT, USA), polyclonal rabbit anti rat cytokeratin 19 (CK-19), anti-insulin, anti-amylase, fluorescein isothiocyanate (FITC) labeled mouse anti rat CD14, CD19, CD29, CD34, CD45, CD73, CD90, and CD105 antibodies (eBioscience, San Diego, CA, USA) were all obtained from commercial sources.

\section{Initial isolation of rat pancreatic duct cells}

Pancreatic duct cells were separated from the rat islet in the whole pancreas using collagenase digestion in situ (Sutton et al., 1986; Peck et al., 2004). Adult male Wistar rats were anesthetized by intraperitoneal injection of $10 \%$ chloral hydrate and median laparotomy was performed. After exposing and pulling aside of the duodenum, the common bile duct, which communicates with the pancreatic duct, was ligated at the ampulla of Vater with $3 / \mathrm{O}$ silk suture. The common hepatic duct was identified and cannulated at the level of the hepatic duct bifurcation. The pancreatic duct was then perfused slowly $(1 \mathrm{~mL} / \mathrm{min})$ with the perfusate consisting of collagenase $\mathrm{V}(1.5 \mathrm{mg} / \mathrm{mL})$, penicillin $(10,000 \mathrm{IU} / \mathrm{mL})$, and streptomycin $(10 \mathrm{mg} /$ $\mathrm{mL}$, in $4^{\circ} \mathrm{C}$ HBSS solution. By injecting $10-12 \mathrm{~mL}$ perfusate into the bile duct, the pancreas became distended and was then quickly excised.

The excised pancreas was placed in a centrifuge tube and incubated in a water bath at $37^{\circ} \mathrm{C}$ for $12-15 \mathrm{~min}$. The pancreas was dispersed by vigorous shaking during this digestion process. Once the pancreas turned into chyle or sand-like particles, HBSS, chilled at $4^{\circ} \mathrm{C}$, was added to stop the digestion. The tube was then centrifuged at $8^{\circ} \mathrm{C}$ for $2 \mathrm{~min}$ at $800 \mathrm{rpm}$. After discarding the supernatant, cells were washed twice with HBSS and then filtered through a $600-\mu \mathrm{m}$ stainless steel mesh. Discontinuous density gradient $(25,23,20.5$, and $11 \%$ Ficoll 400) centrifugation was performed at $4{ }^{\circ} \mathrm{C}$ for $10 \mathrm{~min}$ at $2400 \mathrm{rpm}$. Following centrifugation islets were mainly observed at the $11 / 20.5$ and $20.5 / 23 \%$ interphases, while exocrine and duct cells mainly located at the $23 / 25 \%$ interphase and at the bottom of the tube. Exocrine and duct cells were collected and washed with HBSS and then resuspended in RPMI 1640 medium.

\section{Primary PDSC culture}

Primary PDSC culture was performed in a dynamic three-dimensional cell culture system, Bello Cell-500. The upper chamber of BelloCell holds a cell immobilizing carrier bed, packed with $5.5 \mathrm{~g}$ BioNOCII ${ }^{\circledR}$ matrices $(865 \pm 5)$. These matrices are composed of $100 \%$ 
polyethylene terephthalate non-woven fabric with a treated surface area of about $2000 \mathrm{~cm}^{2} / \mathrm{g}$. While the compressive lower chamber (bellows) contain medium, the movement of which is controlled by a BelloStage console. The compression of bellows (UP) sends the medium into the upper chamber to bring nutrition and remove waste from cells, while the expansion of bellows (Down) return the medium to bellows, exposing the carrier disks to the atmospheric environment (Figure 1).

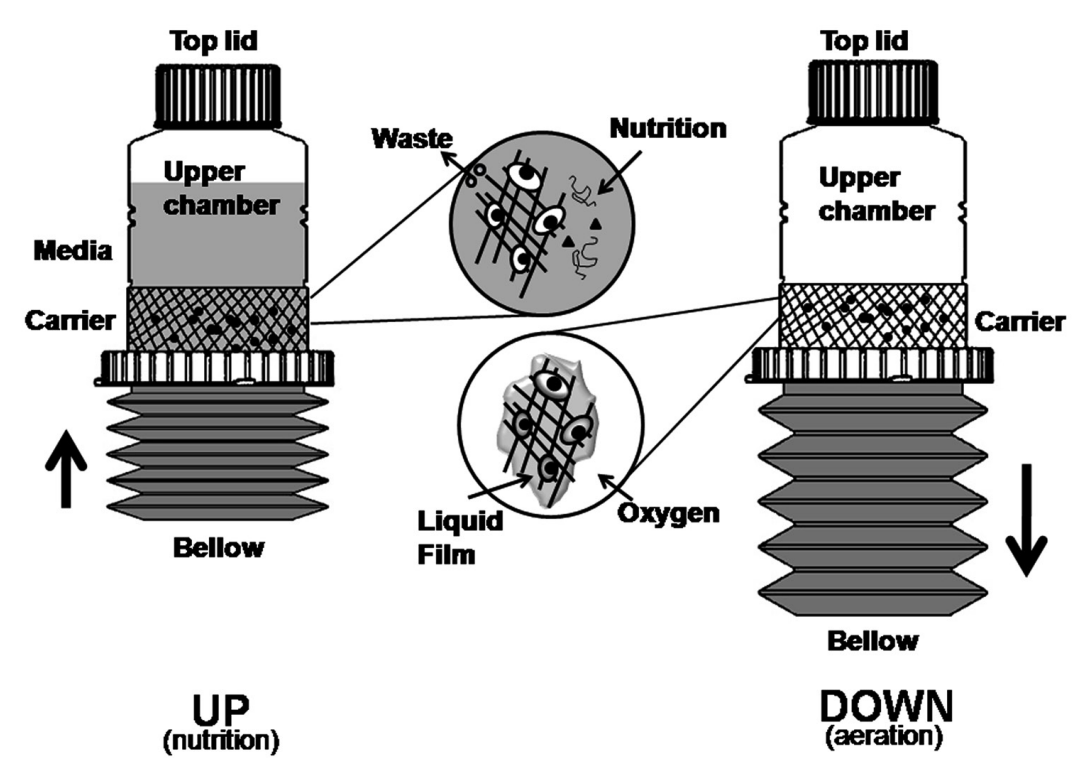

Figure 1. Diagram showing the nutrition and aeration phase during cell culture in the BelloCell system.

RPMI1640 medium (450 mL) supplemented with 10\% FBS was placed in the bellow. Collected cells $\left(1 \times 10^{8}\right)$ were suspended in $50 \mathrm{~mL}$ of RPMI1640 medium containing $10 \%$ FBS and antibiotics (100 U/mL penicillin and $100 \mu \mathrm{g} / \mathrm{mL}$ streptomycin). After mixing, the cells were seeded onto a three-dimensional scaffold in the BelloCell system. Cultures were maintained at $37^{\circ} \mathrm{C}$ in $5 \% \mathrm{CO}_{2}$ and saturated humidity. Initially, the BelloStage system was maintained at an up/down speed of $2.0 \mathrm{~mm} / \mathrm{s}$ and an upper holding time (UH) of $20 \mathrm{~s}$ for adhesion of the cells with the BioNOCII carrier. Once $>95 \%$ of the cells were attached to the matrix in about 3-5 h, the linear moving rate was set at an up/down speed of $1.5 \mathrm{~mm} / \mathrm{s}$ with a $\mathrm{UH}$ of $0 \mathrm{~s}$ and bottom holding time (BH) of $40 \mathrm{~s}$ for cell growth. The growth of PDSCs was checked on a daily basis during the culture.

Total cell numbers were counted and the cells that did not adhere to the scaffolds were discarded. In addition, residual glucose and glutamine concentrations were monitored each day. When glucose or glutamine concentration was low, the culture was replenished with fresh RPMI 1640 medium.

\section{Expansion of PDSCs}

When the adherent cells were $80-90 \%$ confluent, the scaffold was washed with $1 \mathrm{X}$ 
phosphate buffered saline (PBS) to remove the residual culture medium containing nonadherent cells. Five hundred milliliters of preheated $\left(37^{\circ} \mathrm{C}\right) \mathrm{PBS} /$ ethylenediaminetetraacetic acid (EDTA) was poured into the BelloCell and the BH was adjusted to $0 \mathrm{~s}$. After running the system for $10 \mathrm{~min}$, the cleaning solution was removed from the BelloCell. This entire step was repeated twice.

Four hundred milliliters trypsin/EDTA $(0.05 / 0.02 \%)$ preheated to $37^{\circ} \mathrm{C}$ was then added to the BelloCell. After running the system for $10 \mathrm{~min}$ and standing for $5 \mathrm{~min}$, the trypsin/EDTA was removed. The BelloCell was tapped for 3-5 min to detach the cells and filled with $400 \mathrm{~mL}$ preheated RPMI1640 medium. The cells were harvested, counted, diluted, and subcultured using the conditions used for the primary culture.

\section{PDSC identification}

\section{Morphological identification}

Three-dimension vector samples were taken out from the Bellocell, fixed with 99\% alcohol for 5 min, washed with PBS, and then stained with Hematoxylin for 10 min. PDSCs were observed by using an inverted microscope. Other samples were fixed with $2.5 \%$ glutaraldehyde at $4^{\circ} \mathrm{C}$ for $2 \mathrm{~h}$ and then cut to the appropriate size for electron microscopy.

\section{Immunophenotyping}

Isolated pancreatic duct cells before culture, primary PDSC cells, and passaged cells were immunostained for CK-19, insulin, and amylase using the Avidin-Biotin-Complex (ABC) method. Pre-cultured cells were suspended and dropped directly onto coverslips. Primary and passaged cells were analyzed after culture on the coverslips. Three coverslips were coated with poly-L-lysine and placed on 6-well plates. Three-dimensional culture vectors were removed and digested with trypsin. Detached cells were collected and seeded at a density of $2 \times 10^{5}$ cells/ well.

Coverslips were fixed with $4 \%$ paraformaldehyde for $1 \mathrm{~h}$ at room temperature, washed with 1X PBS 3 times, incubated with $3 \% \mathrm{H}_{2} \mathrm{O}_{2}$ for 10 min followed by 3 washes with $1 \mathrm{X}$ PBS. BSA (5\%) was added as the blocking buffer for $20 \mathrm{~min}$ at room temperature. Polyclonal rabbit anti-rat antibodies were diluted (anti CK-19, 1:100; anti-insulin, 1:200; anti-amylase, 1:100) and added as primary antibodies for $1 \mathrm{~h}$ at $37^{\circ} \mathrm{C}$, then washed with $1 \mathrm{X}$ PBS 3 times. Biotinylated goat anti-rabbit IgG was added as the secondary antibody for $20 \mathrm{~min}$ at $37^{\circ} \mathrm{C}$, followed by 3 washes with $1 \mathrm{X}$ PBS. Cells were incubated with the streptavidin-biotin complex $(\mathrm{SABC})$ at $37^{\circ} \mathrm{C}$ for $20 \mathrm{~min}$, washed 3 times with $1 \mathrm{X}$ PBS, colored with diaminobenzidine (DAB), stained with hematoxylin, and observed under an inverted microscope.

\section{Flow cytometry}

When growing PDSCs reach $90 \%$ confluence, 10 to 20 vectors were taken out for examination. PDSCs were digested off from the vectors with $0.1 \%$ collagenase I, washed twice with $1 \mathrm{X}$ PBS, counted, and $1 \times 10^{5}$ of cells were loaded into $1.5 \mathrm{~mL}$ eppendorf tube. These cells were incubated with mouse anti-rat CD14, CD19, CD29, CD34, CD45, CD73, CD90, 
and CD105 antibodies labeled with FITC, at $4^{\circ} \mathrm{C}$ for 30 min and washed twice with $1 \mathrm{X}$ PBS. Phenotypic characterization of PDSCs was performed by FACS Calibur (BD Biosciences) and the results were analyzed with Cell Quest software.

\section{Directed differentiation of PDSCs into insulin-secreting cells}

When $80-90 \%$ of the PDSCs formed clusters, the medium in the BelloCell was discarded and the cells were collected transferred into a $50 \mathrm{~mL}$ centrifuge tube for subsequent differentiation. Matrigel matrix glue $\left(50 \mu \mathrm{L} / \mathrm{cm}^{2}\right)$ was added to cover the entire cell culture surface. The cells were incubated at $37^{\circ} \mathrm{C}$ for $1 \mathrm{~h}$. The cells were resuspended in $50 \mathrm{~mL}$ RPMI1640 medium and evenly seeded onto the scaffolds of the BelloCell, which was then filled with $450 \mathrm{~mL}$ serum-free differentiation medium (1:1 DMEM/F12, with $2 \mathrm{~g} / \mathrm{L} \mathrm{BSA}, 10$ $\mathrm{mM} / \mathrm{L}$ nicotinamide, $10 \mathrm{ng} / \mathrm{mL}$ KGF, $20 \mathrm{ng} / \mathrm{mL} \beta-F G F, 100 \mathrm{U} / \mathrm{mL}$ penicillin, and $100 \mu \mathrm{g} / \mathrm{mL}$ streptomycin). The up/down speed of the BelloStage system was set to $2.0 \mathrm{~mm} / \mathrm{s}$. The UH and $\mathrm{BH}$ times were $20 \mathrm{~s}$ and $0 \mathrm{~s}$, respectively. After an initial 2-h run, the up/down speed was decreased to $1.5 \mathrm{~mm} / \mathrm{s}$, with the UH time decreased to $0 \mathrm{~s}$ and the $\mathrm{BH}$ time increased to $40 \mathrm{~s}$. The cell incubator was maintained at $37^{\circ} \mathrm{C}$ with $5 \% \mathrm{CO}_{2}$ and saturated humidity. The medium was replaced every 2 days. The samples were observed on a daily basis until obvious islet-like cell clusters (ICCs) were identified.

\section{ICC identification}

The morphology of the differentiated cell clusters was observed using light microscopy and samples were immunostained for insulin markers.

\section{Qualitative measurement of insulin by DTZ staining}

Two weeks after differentiation, a portion of the scaffolds was removed from the BelloCell and subsequently digested with trypsin. Detached cells were placed in the differentiation medium, and DTZ (20 mg DTZ: $6 \mathrm{~mL}$ ethanol: $100 \mu \mathrm{L}$ concentrated aqueous ammonia) was added at $10 \mu \mathrm{L}$ per $1 \mathrm{~mL}$ culture medium. After incubation at $37^{\circ} \mathrm{C}$ for $15 \mathrm{~min}$, the stained cells were observed under a light microscope.

\section{Quantitative measurement of insulin}

After two weeks of differentiation, the insulin levels in the extracellular fluid and the cell lysis supernatant of the ICCs were measured. Undifferentiated cells were used as a control. A portion of the scaffolds was removed from the BelloCell and the cells were trypsinized off the wall. After centrifugation, the harvested cells were placed on 12-well plates and incubated sequentially in either low glucose $(5.6 \mathrm{mM} / \mathrm{L})$ or high glucose $(24.8 \mathrm{mM} / \mathrm{L}) \mathrm{DMEM}$ at $37^{\circ} \mathrm{C}$ for $4 \mathrm{~h}$. Culture supernatants were collected and stored at $-70^{\circ} \mathrm{C}$. In addition, a portion of the differentiated cells was collected and lysed with an acid-ethanol solution (cell lysis buffer) for $30 \mathrm{~min}$ on ice. During the lysis, the cells were gently pipetted to ensure complete cleavage. Lysates containing the cell debris were transferred into a $1.5 \mathrm{~mL}$ microcentrifuge tube and centrifuged at $4^{\circ} \mathrm{C}$ for $5 \mathrm{~min}$ at $12,000 \mathrm{rpm}$. After centrifugation, the supernatant was 
transferred into a $0.5 \mathrm{~mL}$ centrifuge tube and stored at $-70^{\circ} \mathrm{C}$. The insulin levels were measured by radioimmunoassay (RIA) and normalized by dividing the amount of total cell proteins.

\section{Statistical analysis}

Significant differences between two groups were evaluated using a one way student t-test analysis of variance with 99\% confidence interval (GraphPad Prism v3.02, GraphPad, San Diego, CA, USA). The differences were considered statistically significant when $\mathrm{P}<0.01$.

\section{RESULTS}

\section{PDSCs could proliferate effectively in the BelloCell bioreactors}

Using $1 \times 10^{8}$ cells as the inoculation cell density, PDSCs could proliferate effectively and reach in average a maximum number of $1.5 \times 10^{9}$ in 7 days. Thus, PDSCs were passaged every 7 days thereafter. Based on the desirable glucose and glutamine concentrations, the timing of the exchange of the medium was determined as 3,5, and 7 days after the beginning of the culture (Figure 2). This experiment was repeated 5 times and representative data are presented.

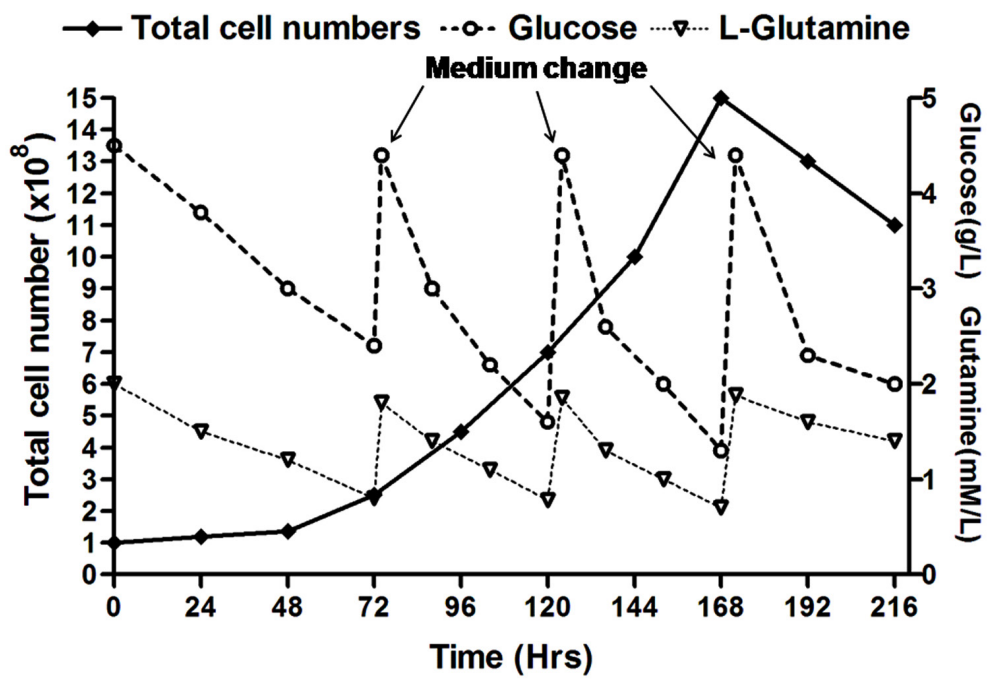

Figure 2. Cell growth and glucose and glutamine concentrations using the BelloCell bioreactor. Arrows show the replacement of the medium.

\section{Morphology of PDSCs}

Cultured cells were observed in the network of scaffold fibers under both a light microscope and a scanning electron microscope. At the beginning of the culture, individual PDSC attached to the fibers and stayed far from each other. After several days of culture, cells 
grew along the fibers and multiple cell populations gradually formed. After 7 days of culture, PDSCs gathered into groups of cells (Figure 3).

After expansion of PDSCs, the morphology was more uniform and no significant difference in the morphology of the proliferated cells was observed. Cells proliferated rapidly and a stable long-term culture could be established with passage every 7 days. The cells could be continuously passaged for 30 generations with no obvious signs of senescence such as increase in cell volume, uneven morphology, increase in intracellular granules, and slow cell proliferation were observed. These PDSCs could be expanded in vitro using dynamic threedimensional cell culture.
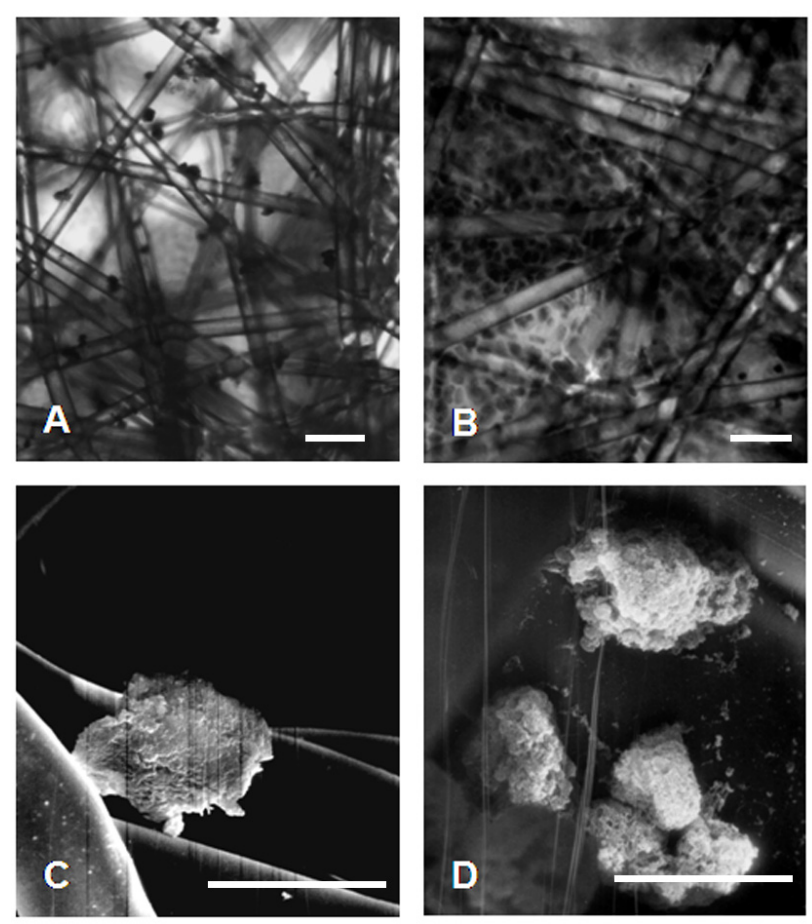

Figure 3. Microscopic findings of PDSCs. PDSCs after 1 day (A) and 7 days (B) of culture in the BelloCell culture system observed under a light microscope. PDSCs at the beginning $(\mathbf{C})$ and after 7 days $(\mathbf{D})$ of culture observed by using a scanning electron microscope. Scale bar $=50 \mu \mathrm{m}$.

\section{PDSCs could be successfully separated from endocrine and exocrine cells}

The majority of freshly isolated cells stained positive for CK-19 (Figure 4A) and amylase was abundantly expressed (Figure 4B). In contrast, they rarely stained positive for insulin (Figure 4C). These results confirmed that these cell populations mainly originated from exocrine tissues of the pancreas, including ducts and acinar cells, but not from the endocrine portion. Pancreatic duct cells, acinar cells, and endocrine cells could be separated by in situ collagenase digestion and discontinuous density gradient centrifugation. After 5 days of primary culture (first generation), adherent cells of primary PDSCs stained positive for CK-19 (Figure 4D), but negative for amylase (Figure 4E). This result indicates that these adhering cells originated from 
pancreatic ducts, but not from an exocrine source. Pancreatic duct cells and acinar cells can be efficiently separated by using a dynamic three-dimensional cell culture system using serumcontaining medium. The 4th generation of passaged cells stained positive for Pdx-1 (Figure 4F), a well-known pancreatic endocrine progenitor cell marker (Jiang and Morahan, 2014).
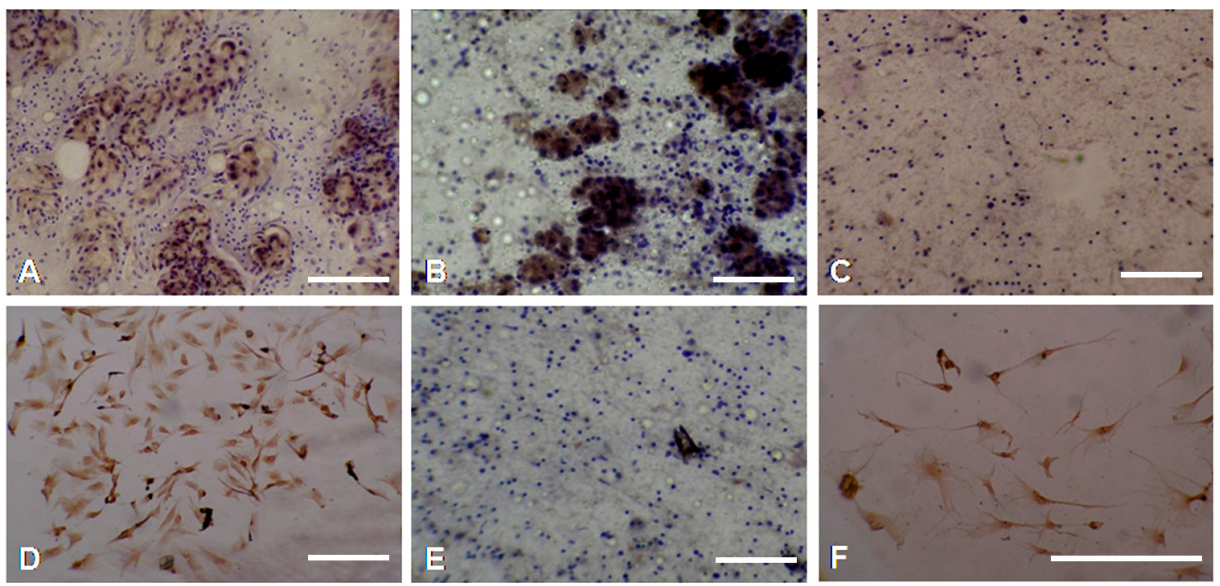

Figure 4. Immunohistological findings of isolated and cultured cells. A. CK-19 positive staining after collection. B. Amylase positive staining. C. Insulin negative staining. D. CK-19 positive staining. E. Amylase negative staining. F. A $3^{\mathrm{RD}}$ generation of culture: PDX-1 positive staining. Scale bar $=50 \mu \mathrm{m}$.

\section{Passaged PDSCs are a type of mesenchymal stem-like cells (MSCs)}

The fourth generations of cultured PDSCs were characterized by flow cytometry. These cells were positively stained for CD29 (86.17\%), CD73 (90.73\%), CD90 (84.13\%), and CD105 (78.28\%) and negatively stained for CD14 (6.25\%), CD19 (9.53\%), CD34 (6.13\%), and CD45 (7.28\%) (Figure 5). This expression pattern of cell surface markers is consistent with that of MSCs, suggesting that PDSCs are a type of MSCs. This experiment was repeated 5 times and representative data are presented.

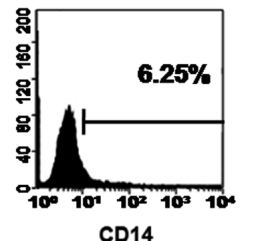

CD14
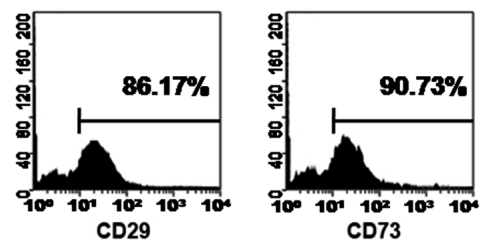
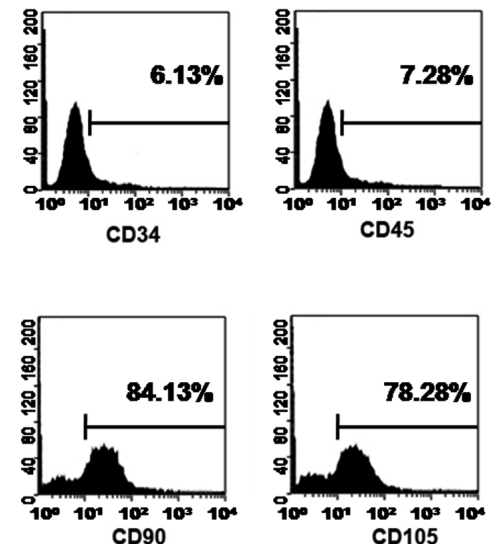

Figure 5. Flow cytometric analysis of the 4th generation of passaged PDSCs. 


\section{PDSCs can be differentiated into ICCs and express insulin}

After 7 days of differentiation, cell clusters were first observed in the network of scaffold fibers (Figure 6A). After 10 days of differentiation, representative ICCs stained positive for insulin (Figure 6B). In addition, the ICCs gradually became regular in morphology over this period. After two weeks of differentiation, representative ICCs exhibited a red color after DTZ staining (Figure 6C). A computerized semi-quantitative analysis showed a specificity of around $70-80 \%$ of positive staining.
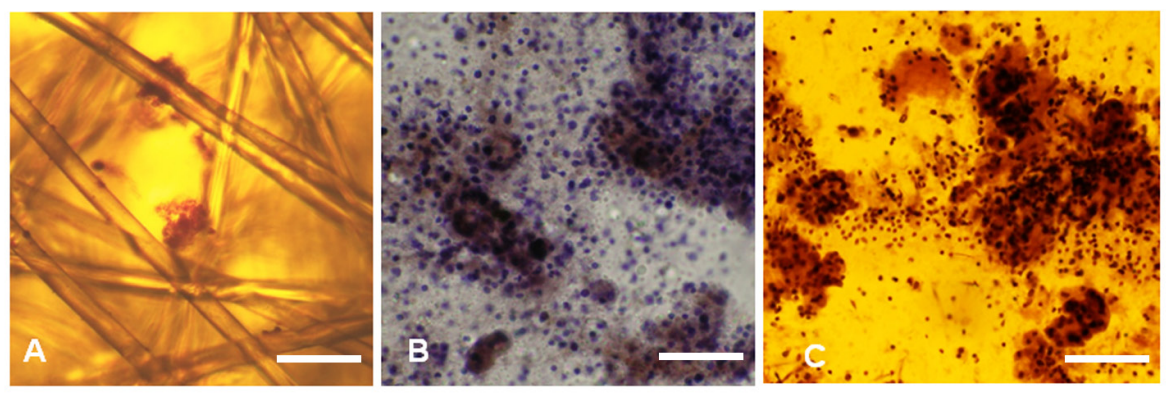

Figure 6. Insulin and DTZ staining of ICCS. A. Cell clusters after 7 days of differentiation observed under a light microscope. B. Insulin- staining of representative ICC after 10 days of differentiation. C. After 2 weeks of differentiation, representative ICC exhibited a red color when stained with DTZ. Scale bar $=50 \mu \mathrm{m}$.

\section{ICCs differentiated from PDSCs highly produced insulin}

After two weeks of dynamic three-dimensional cell culture, the insulin levels in both the extracellular fluid and cell lysate supernatant of the ICCs were significantly higher than that of the undifferentiated PDSCs $(\mathrm{P}<0.01)$ However, under high glucose stimulation, these differentiated ICCs could not secrete amounts of insulin comparable to those secreted by mature islet cells $(\mathrm{P}<0.01)$ (Table 1).

Table 1. Insulin levels in the extracellular fluid and cell lysate supernatant of PDSCs and ICCs after threedimensional culture.

\begin{tabular}{l|c|c|c|c|c}
\hline Samples & $\begin{array}{c}\text { Glucose in medium } \\
(\mathrm{mM})\end{array}$ & $\begin{array}{c}\text { Undifferentiated PDSCs } \\
(\mathrm{mIU} / \mathrm{L})\end{array}$ & $\begin{array}{c}\text { Differentiation into ICCs for 2 weeks } \\
(\mathrm{mIU} / \mathrm{L})\end{array}$ & Islet cells (mIU/L) & P value \\
\hline Extracellular fluid & Low 5.5 & $0.39 \pm 0.15$ & $17.21 \pm 2.24^{*}$ & $18.47 \pm 3.62$ & $<0.01$ \\
\cline { 2 - 6 } & High 24.8 & $0.28 \pm 0.13$ & $24.11 \pm 2.17^{*}$ & $57.24 \pm 2.16^{\#}$ & $<0.01$ \\
\hline Cell lysis supernatant & & $0.15 \pm 0.02$ & $10.67 \pm 1.76^{*}$ & $<0.01$ \\
\hline
\end{tabular}

*Compared with undifferentiated PDSCs, ${ }^{*}$ compared with differentiated ICCs.

\section{DISCUSSION}

Islet transplantation for the treatment of diabetes requires a large number of islets. Development of new sources of islets has become a popular topic of research (Sachs and Bonner-Weir, 2000). The discovery of stem cells provided a new potential source of islets. In recent years, progress has been made in the study of pancreatic stem cells. Mesenchymal stromal cells from islets can expand 1000 times in vitro, while levels of glucagon and insulin 
mRNA remained undetectable (Behrous et al., 2007). This suggests that the expanded cells maintained the characteristics of precursors or stem cells. To date, pancreatic duct- and isletderived stem cells have been successfully differentiated into glucose-responsive insulinsecreting cells (Zulewski et al., 2001). However, pancreatic stem cells require in vitro expansion to a large number and differentiation into mature pancreatic $\beta$-cells before they can be used in the clinic. Expansion and differentiation are two separate stages of growth of pancreatic stem cells. However, they overlap and are hard to distinguish. It has been reported that rapidly proliferating cells present a weak capacity for differentiation, whereas cells with a strong ability to differentiate proliferate slowly. Balancing proliferation and differentiation and maximizing the yield of fully functional islet cells remain a challenge.

Three dimensional cell culture (TDCC) is a technology in which cells are cultured within the three-dimensional scaffolds composed of different materials. This system enables cells to migrate, grow in the three-dimensional spatial structures of the scaffolds, and form threedimensional cell-scaffold complexes. The cell growth environment created by this technology may fully simulate the in vivo environment. A number of researchers have achieved good results when applying dynamic TDCC technology to autologous tissue-engineered cartilage (Lü et al., 2007), tumor cells, and fibroblasts (He et al., 2003). Oxygen transfer limitation has been a concern for high-density cell culture. The bioreactor used in the present study was filled with a large number of scaffolds, which provided a large surface area for oxygen transmission. Therefore, minimal diffusion is needed by the cells attached to the scaffolds. This system not only effectively provides the required oxygen, but also allows the cells to adhere and proliferate under low shear stress and in a bubble-free environment. This technology also increases the area to which the cells can adhere, effectively supporting high production yields.

In our study, PDSCs successfully grew in aggregates for more than 30 generations. Moreover, the differentiated islet-like cell clusters were located in the network of fibers of the three-dimensional scaffold. After two weeks of differentiation in the dynamic threedimensional culture, the resulting ICCs expressed detectable levels of insulin, as confirmed by immunocytochemistry and DTZ staining. Both intracellular and extracellular insulin levels were significantly higher than those of undifferentiated PDSCs. This suggests that, after differentiation, PDSCs were able to synthesize and release insulin from the cytoplasm to the extracellular medium. However, under high glucose stimulation, these differentiated ICCs still cannot secrete amounts of insulin comparable to those produce by normal islets, indicating that the resulting cells are less functional than normal islet cells. Further exploration and improvement of in vitro differentiation of pancreatic stem cells is the key to their clinical application.

In conclusion, in this study, PDSCs proliferated and differentiated effectively in the dynamic three dimensional culture and represent a potential clinical cell therapy for patients with type I diabetes.

\section{Conflicts of interest}

The authors declare no conflict of interest.

\section{ACKNOWLEDGMENTS}

The authors are funded by Special Research Fund for the Doctoral Program of 
Liaoning province (\#2011225020), National natural science foundation of China (\#81373173), and the Specialized Research Fund for the Doctoral Program of Higher Education of China (\#20132104120002).

\section{REFERENCES}

Behrous D, Laertis I and Bruce MR (2007). Human islet-derived precursor cells are mesenchymal stromal cells that differentiate and mature to hormone-expressing cells in vivo. Stem Cells 25: 3215-3222.

Bhonde R.R., Sheshadri P., Sharma S., Kumar A. (2014) Making surrogate $\beta$-cells from mesenchymal stromal cells: Perspectives and future endeavors. Int. J. Biochem. Cell Biol. 46:90-102.

Bonner-Weir S and Weir GC (2005). New sources of pancreatic beta-cells. Nat. Biotechnol. 23: 857-861. http://dx.doi. org/10.1038/nbt1115

Chhabra P and Brayman KL (2013). Stem cell therapy to cure type 1 diabetes: from hype to hope. Stem Cells Transl. Med. 2: 328-336. http://dx.doi.org/10.5966/sctm.2012-0116

Davani B, Ikonomou L, Raaka BM, Geras-Raaka E, et al. (2007). Human islet-derived precursor cells are mesenchymal stromal cells that differentiate and mature to hormone-expressing cells in vivo. Stem Cells 25: 3215-3222. http:// dx.doi.org/10.1634/stemcells.2007-0323

He C, Deng LF and Zhu YP (2003). Experiment on fibroblast-PGA complexes cultured in rotary cell culture system. Zhonghua Wai Ke Za Zhi 41: 214-217.

Jiang FX and Morahan G (2014). Pancreatic Stem Cells Remain Unresolved. Stem Cells Dev. 23: 2803-2812

Lü CW, Hu YY, Bai JP, Liu J, et al. (2007). Three dimensional induction of autologous mesenchymal stem cell and the effects on depressing long-term degeneration of tissue-engineering cartilage. Zhonghua Wai Ke Za Zhi 45: 1717-1721.

Minami K and Seino S (2013). Current status of regeneration of pancreatic $\beta$-cells. J. Diabetes Investig. 4: 131-141. http:// dx.doi.org/10.1111/jdi.12062

Peck AB, Yin L and Ramiya V (2004). Animal models to study adult stem cell-derived, in vitro-generated islet implantation. ILAR J. 45: 259-267. http://dx.doi.org/10.1093/ilar.45.3.259

Ramiya VK, Maraist M, Arfors KE, Schatz DA, et al. (2000). Reversal of insulin-dependent diabetes using islets generated in vitro from pancreatic stem cells. Nat. Med. 6: 278-282. http://dx.doi.org/10.1038/73128

Sachs DH and Bonner-Weir S (2000). New islets from old. Nat. Med. 6: 250-251. http://dx.doi.org/10.1038/73079

Schiesser JV and Wells JM (2014) Generation of $\beta$ cells from human pluripotent stem cells: Are we there yet? Ann. N. Y. Acad. Sci. 1311: 124-137.

Shapiro AM, Ricordi C, Hering BJ, Auchincloss H, et al. (2006). International trial of the Edmonton protocol for islet transplantation. N. Engl. J. Med. 355: 1318-1330. http://dx.doi.org/10.1056/NEJMoa061267

Sutton R, Peters M, McShane P, Gray DW, et al. (1986). Isolation of rat pancreatic islets by ductal injection of collagenase. Transplantation 42: 689-691. http://dx.doi.org/10.1097/00007890-198612000-00022

Wang IK, Hsieh SY, Chang KM, Wang YC, et al. (2006) A novel control scheme for inducing angiostatin-human IgG fusion protein production using recombinant $\mathrm{CHO}$ cells in a oscillating bioreactor. J. Biotechnol. 121: 418-428.

Zulewski H, Abraham EJ, Gerlach MJ, Daniel PB, et al. (2001). Multipotential nestin-positive stem cells isolated from adult pancreatic islets differentiate ex vivo into pancreatic endocrine, exocrine, and hepatic phenotypes. Diabetes 50 : 521-533. http://dx.doi.org/10.2337/diabetes.50.3.521 